\title{
Multiple breakage of a covered esophageal stent
}

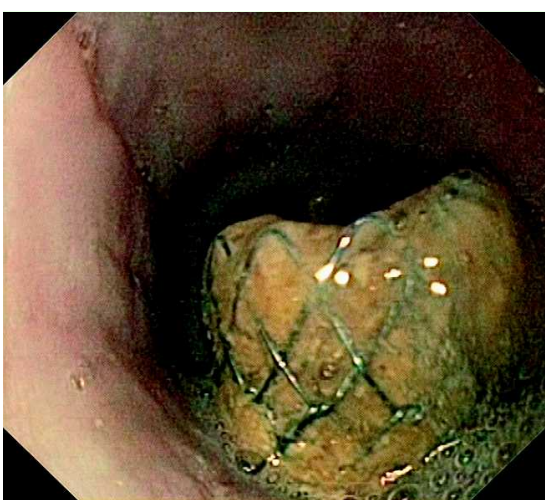

Fig. 1 Endoscopy showing an unusual oblique position of the proximal stent end.

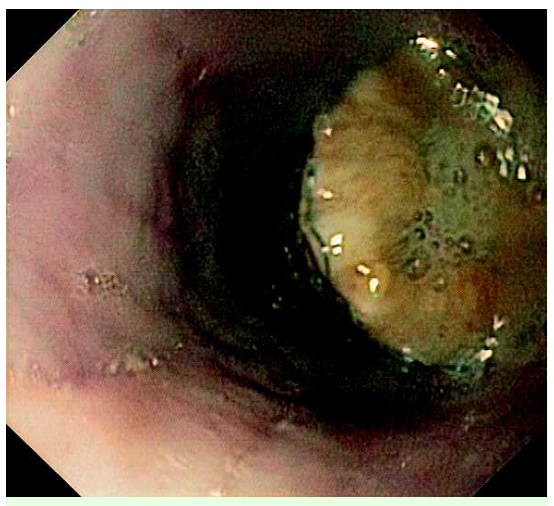

Fig. 2 Another view of the proximal end of the fully occluded stent.

A 59-year-old patient presented with recurrent dysphagia 7 months after successful insertion of an esophageal covered metal stent (Choo-Stent; M.I.Tech Co., Ltd., Seoul, Korea). The stent had been in-

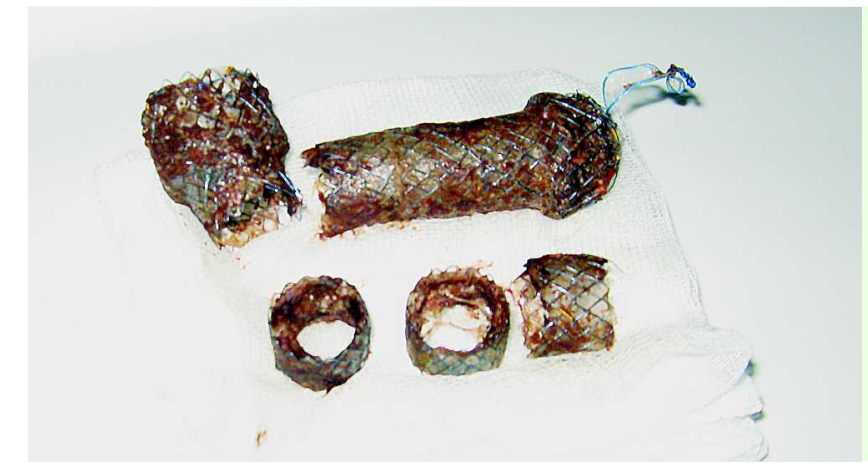

Fig. 3 Extracted stent fragments.

serted with palliative intent because of an obstructive T4 esophageal squamous cell cancer that was penetrating into the (already stented) trachea. After the esophageal stenting and subsequent chemotherapy the patient had initially made a very good recovery.

Endoscopy now showed that the esophageal stent was in a horizontal position and occluded with food particles ( $\bullet$ Fig. 1 and 2). When the proximal end of the stent was grasped, it proved, surprisingly, to have broken into five fragments, which were removed without problems ( $\bullet$ Fig. 3). Once the fragments were removed, the esophageal passage was free. No further intervention was necessary, and to date the patient has not complained again of recurrent dysphagia. Repeat endoscopy 2 months later

\section{P. Born}

Department of Internal Medicine, Tirschenreuth District Hospital, Tirschenreuth, Germany

Bibliography

DOI 10.1055/s-2008-1077406

Endoscopy 2009; 41: E34-E34

(c) Georg Thieme Verlag KG Stuttgart · New York . ISSN 0013-726X

\section{Corresponding author}

\section{Peter Born MD}

Department of Internal Medicine

Tirschenreuth District Hospital

St.-Peter-Straße 31

95643 Tirschenreuth

Germany

Fax: 09631-875210

peter.born@krankenhaus-tirschenreuth.de 